\title{
Quality Assessment Statistic Evaluation of $X$-Ray Fluorescence via NIST and IAEA Standard Reference Materials
}

\author{
O. M. H. Ahmed ${ }^{1,2 *}$, Farouk I. Habbani' ${ }^{3}$, A. M. Mustafa², E. M. A. Mohamed ${ }^{4}$, A. M. Salih', \\ Ftihia Seedig 3
}

${ }^{1}$ Chemistry and Nuclear Physics Institute, Sudan Atomic Energy Commission, Khartoum, Sudan

${ }^{2}$ College of Nuclear Science and Technology, Harbin Engineering University, Harbin China

${ }^{3}$ Department of Physics, Faculty of Science, University of Khartoum, Khartoum, Sudan

${ }^{4}$ Council of Atomic Energy, Sudan Academy of Sciences, Khartoum, Sudan

Email: *osama@hrbeu.edu.cn, *osama.alagra@yahoo.com

How to cite this paper: Ahmed, O.M.H., Habbani, F.I., Mustafa, A.M., Mohamed, E.M.A., Salih, A.M. and Seedig, F. (2017) Quality Assessment Statistic Evaluation of X-Ray Fluorescence via NIST and IAEA Standard Reference Materials. World Journal of Nuclear Science and Technology, 7, 121-128.

http://doi.org/10.4236/wjnst.2017.72010

Received: January 10, 2017

Accepted: April 27, 2017

Published: April 30, 2017

Copyright $\odot 2017$ by authors and Scientific Research Publishing Inc. This work is licensed under the Creative Commons Attribution International License (CC BY 4.0).

http://creativecommons.org/licenses/by/4.0/

(c) (i) Open Access

\begin{abstract}
The aim of this study is a quality assessment of X-ray fluorescence laboratory located at the University of Khartoum. The X-ray fluorescence spectrometer system consists, a set of three ${ }^{109} \mathrm{Cd}$ sources of an initial nominal activity of 10 $\mu \mathrm{Ci}$, and $\mathrm{Si}(\mathrm{Li})$ detector Energy Dispersive $\mathrm{XRF}(\mathrm{EDXRF})$ systems. It is important to carry out this work because it has an effective contribution for a wide range of research and services. The assessment was carried out by measuring 8 NIST-2709a (soil) and 13 IAEA-155 (milk powder) standard reference material samples for repeatability examinations to test the measurement precision. The total combined standards uncertainty values for XRF lab were estimated by an error from repeatability measurements adding $2.6 \%$ for error propagation related to the method. For accuracy assessment, three standard statistic approaches were applied, i.e. the Bias \%, zeta-score, and $E_{n}$-number. The bias of all elements for both standard materials was found to be within a deviation range from $-28 \%$ to $7.8 \%$. The results of all elements for both the zeta-score test and $E_{n}$-number have satisfactory results except Th (Thorium) and $\mathrm{Zr}$ (Zirconium) which consider as questionable results for NIST SRM 2709a and unsatisfactory results for $E_{n}$-number.
\end{abstract}

\section{Keywords}

XRF, QC, Reference Material, Statistic Evaluation

\section{Introduction}

$\mathrm{X}$-ray fluorescence analysis (XRF) is a powerful physical technique, which is a 
nondestructive instrumental method for qualitative and quantitative analysis of chemical elements [1]. It is based on measurements of energies and intensities of the X-ray spectral lines emitted by secondary excitation of the elements of interest. The primary beam of photons from an X-ray source strikes the specimen (sample or standard). The absorption of these photons by photoelectric effect produces vacancies in the inner electron shells of the atoms of the material. Electrons from the outer shells transfer to fill these vacancies, followed by the emission of secondary spectral lines having characteristic energies of the element (the basis of qualitative analysis), and intensities related to its concentrations [2].

The experimental measurement of the sample is interested to be analyzed for elemental composition is irradiated using X-ray from an X-ray source $\left({ }^{109} \mathrm{Cd}\right.$, ${ }^{55} \mathrm{Fe},{ }^{241} \mathrm{Am}$ or tube excitation), the characteristic X-rays of the elements present in the sample are produced during the irradiation can be detected by an $\mathrm{x}$-ray detector. The charge can be collected by the detector provides an electrical signal proportional to the X-ray energies are emitted. This signal processes to a preamplifier mounted with the detector, which integrates each detector signal to produce a voltage pulse proportional to the charge. This pulse is then amplified and shaped by a linear amplifier. The amplified signal is processed and displayed in a multi-channel analyzer (MCA) which is connected directly to a computer where the X-ray spectrum is analyzed [3] [4]. Currently, the energy dispersive radioisotope source X-ray fluorescence (EDXRF) instruments are available two basic detector types; high-resolution, low-temperature solid-state detectors (based on lithium drifted silicon) and lower-resolution, gas-filled proportional counters [5].

One of the most important analytical chemistry laboratories in Sudan is X-ray fluorescence laboratory, it is located at The University of Khartoum ( $\mathrm{U}$ of $\mathrm{K}$ ), Khartoum, it has been installed in 1982 under framework of technical assistance by International Atomic Energy Agency (IAEA) to support Sudan for nuclear science education, training, and applications. An X-ray spectrometer system was supplied within that project to establish a nuclear science laboratory to service both undergraduate and research students as well research in the radio-analytical field in the country. It is presently applied in the analysis of various samples, including environmental samples, biological samples such as plants, human and animal tissues, geological samples, ... etc. However, it is important to carry out this work because it has an effective contribution in the wide range of research and services.

The objective of the present work is a quality assessment for of X-ray fluorescence spectroscopy system statistically. The assessment can be achieved by analyzing a known materials, two Standard Reference Materials (SRMs): NIST2709a, soil SRM [6] (National Institute of Standards) and IAEA-155, Whey Powder (International Atomic Energy Agency) [7] the different statistical standard test has been used in this is study include the relative standard deviation (\%) to evaluate measurements precision. For accuracy evaluation, three statistical tests have been carried out including relative bias (\%), Zeta-score and $E_{n}$-number test which is consider as standard statistic approach according to ISO 13528: 2015(E) 
[8] and it is the most frequently used in proficiency testing to determine the performance of laboratory which can describe the important laboratory parameters: bias, stability, and repeatability. The evaluation can be carried out by comparing the measurements values with certified values.

\section{Material and Method}

About $1 \mathrm{~g}$ of two dried standard reference material samples (NIST2709a and IAEA-155) were homogenized for 15 minutes and prepared in the form of pressed powder pellets at 15 ton with area $4.901 \mathrm{~cm}^{2}$ using 25 tons pressing machine to be ready for measurements. The analysis of 8 and 13 pellets of NIST2709a and IAEA155, standard reference materials respectively were carried out using Energy Dispersive XRF(EDX) analysis system Canberra Company (Model 3501, serial number 9,861,180 made in the USA). The samples were irradiated using a set of three ${ }^{109} \mathrm{Cd}$ sources of an initial nominal activity of $10 \mu \mathrm{Ci}$. The $\mathrm{x}$-ray fluorescence that is present from the element in samples were detected by $\mathrm{Si}(\mathrm{Li})$ detector systems, integrated with preamplifier, amplifier, negative high voltage $(600 \mathrm{~V})$ (Canberra model number 7013-04755 and serial number 10-3499), and Separate Multi-Channel Analyzer (MCA) (series 35-Canberra). The energy resolution of the detector was $190 \mathrm{eV}$ at $5.8 \mathrm{KeV}$ of Mg. The analysis of X-ray spectra is carried out using a computer program called Analysis of $\mathrm{X}$-ray Spectra by Iterative Least-Square fitting (AXIL), which is a Fortran program developed by Van Espen for the deconvolution of complex X-ray spectra by $\mathrm{Si}(\mathrm{Li})$ detector. The error was evaluated from the AXIL program included the counting statistical errors of measured X-ray intensities, as well as errors in the mathematical procedure utilized in the fitting of the experimental spectral data.

The moisture of each reference material separately dried at $105^{\circ} \mathrm{C}$ for $40 \mathrm{mi}$ nutes under distributor with silica gel to obtain the moisture content and dry mass factor was corrected.

The average values of concentrations for major and minor constituents were calculated and compared with the reference data. The combined standard uncertainty was estimated according to error propagation for the interesting element. The standard deviation of all measurements was examined for reproducibility. The accuracy of element determination was compared with certified values and evaluated statistically using relative bias, Zeta-score and $E_{n}$ number test.

\section{Statistical Evaluation}

\section{Combine standard uncertainty}

The combine Standard uncertainty of measurement $\left(U_{c}\right)$ is obtained by combining the individual standard uncertainties $U_{i}$ from type $A$ and type $B$ error. This method is known as the law of propagation of uncertainty [9] which is equal to the positive square root of a sum of terms, the terms being the variances or covariances of these other quantities weighted according to how the measurement result varies with changes in these quantities [9] and is calculated as follows: 


$$
U_{\text {Lab }}=K \sqrt{(S D)^{2} / n+U_{\text {method }}^{2}}
$$

where $S D$ is the standard deviation of $(n)$ replicate independent measurement and $U_{\text {method }}$ is the estimated uncertainty of interested method. $K$ is coverage factor which gives particular confidence level where $k=1$ for combined standard and uncertainty and $k=2$ for expanded uncertainty [8] [10].

\section{Relative Bias Test:}

Relative bias (\%) is used to calculate the relation between the assigned value and measured value to investigate the systematic error. The $R B$ shows that the experimental results are within the confidence interval of $95 \%$ [11]

$$
\boldsymbol{R B}=\frac{\text { Value }_{\text {Lab }}-\text { Value }_{\text {Assigned }}}{\text { Value }_{\text {Assigned }}} \times 100 \%
$$

\section{Zeta-score Test:}

Zeta-scores is used for improving the performance of laboratories [8] which is calculated as:

$$
\text { Zeta-score }=\frac{\text { value }_{\text {lab }}-\text { value }_{\text {assinged }}}{\sqrt{U_{\text {Lab }}^{2}+U_{\text {assinged }}^{2}}}
$$

where $\left(U_{L a b}\right)$ and $\left(U_{\text {assigned }}\right)$ is standard uncertainties of certified and measured value at $95 \%$ CI based on the Zeta-scores for laboratory performance is evaluated following decision limits were established: $|z| \leq 2$ : a satisfactory result $2<|z|<3$ : the result is considered questionable $|z| \geq 3$ : the result is considered unsatisfactory [12].

\section{$E_{\text {n-number Test: }}$}

$E_{n}$-number is statistical parameter use for accuracy evaluation which defined as absolute different between the experimental result $\left(\right.$ Value $_{\text {Lab }}$ ) and assigned value ( Value assigned $_{\text {) }}$ of elemental concentrations divided by squared of expanded uncertainties where it is equal two combined standard uncertainty of certified $\left(U_{\text {assigned }}^{2}\right)$ and experimental value $\left(U_{\text {Lab }}^{2}\right)[13]$ as showing at equation

$$
E_{n}=\frac{\mid \text { Value }_{\text {Lab }}-\text { Value }_{\text {assigned }} \mid}{\sqrt{U_{\text {Lab }}^{2}+U_{\text {assigned }}^{2}}}
$$

The $E_{n}$-number is commonly used 1.0 as critical value where $\left|E_{n}\right|<1$ consider as accepted result this because it calculated using expanded uncertainties and using in this study to evaluate the estimated uncertainty [14].

\section{Results and Discussion}

Figure 1 shows the obtained relative standard deviation result for element concentration repeatability for both SRM. The result shows that most of the elements have less than $15 \%$ except $\mathrm{Fe}$ (19.1\%) on IAEA-155, Ni (25.5\%) on NIST-2709a have higher that due to the concentrations are close to the detection limit of this is an element. 


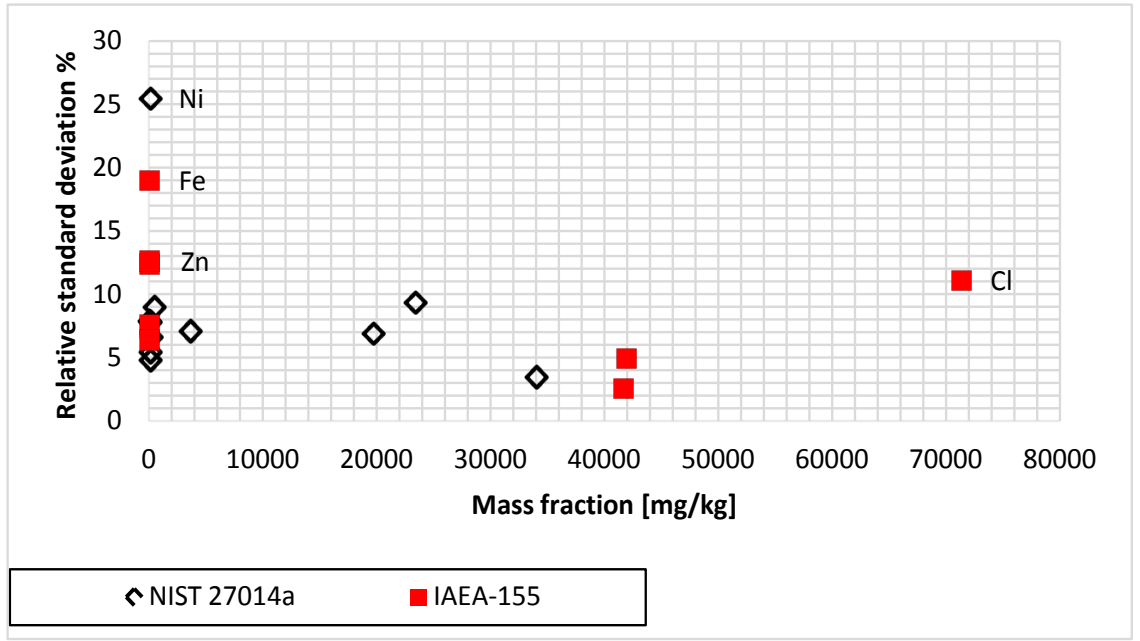

Figure 1. Repeatability of measured mass fraction for different element on NIST2709a and IAEA-155 standard reference material.

The method uncertainty was estimated as combined standard uncertainty with coverage factor $(k=1)$ as $2.6 \%$ at $95 \%$ Confidence interval (CI) according to error propagation of uncertainty sources, the standard error (1\%), absorption and enhancement by matrix (2\%), positioning of sample $(0.5 \%),{ }^{109} \mathrm{Cd}$ dimensions $(0.2 \%),{ }^{109} \mathrm{Cd}$ photons output (1\%) and homogeneity of sample $(0.5 \%)$. The calculation was carried out according to the positive square root of a sum uncertainty sources. The total combined standard uncertainties were calculated using Equation (1) for measurement repeatability see Table 1.

Table 1 present the analytical results of NIST2709a and IAEA-155 as well as assigned values with uncertainty at a confidence level of $95 \%$. The uncertainty of measured elements on IAEA-155 were found to be between 3\% to 5\% and from $3 \%$ to $9 \%$ for NIST2709 a see Table 1 . Three statistical test relative bias \%, Zeta-score, and $E_{n}$-number of the results were carried out. Figure 2 shows the ratios between measured and assigned value for the NIST2709a and IAEA-155 reference materials. It is important to note that the results obtained were randomly above and below the assigned values, showing that there is no systematic error. Experimental values and assigned values for all element expect $\mathrm{Th}$ and $\mathrm{Zr}$ have good agreement with concentrations reported in the certificate. Th and $\mathrm{Zr}$ are deviated by $23 \%$ and $39 \%$.

For accuracy investigation, the measured value and certified value statistically compared by bias \%, Zeta-score, and $E_{n}$-numbers see Figure 3 and Figure 4 . The certified values in NIST SRM 2709a, show the bias (\%) is relatively higher for both $\mathrm{Th}(19 \%)$ and $\mathrm{Zr}(28 \%)$ and all results obtained for other elements have good agreement with assigned values. Figure 3 shows on Zeta-score test that all the results of NIST SRM 2709a and IAEA-155 are within 95\% CI. Satisfactory results were obtained except $\mathrm{Zr}$ (2.19) and $\mathrm{Th}$ (2.83) showing to be as questionable results in NIST SRM 2709a. Figure 4 shows that $E_{n}$-number test for all elements for both SRMs were accepted, except Th and Zr in NIST SRM 2709a which are show as unsatisfied result. 
Table 1. Statistical evaluation of NIST2709a and IAEA-155 Standard reference material based on elemental determination by ${ }^{109} \mathrm{Cd}$ radio-isotopic excitation source for $(n)$ replicates in $\mathrm{mg} \cdot \mathrm{kg}^{-1}$ (dry mass basis) applying AXIL software (adding $2.6 \%$ estimated uncertainty of XRF of UK lab).

\begin{tabular}{|c|c|c|c|c|c|c|c|c|}
\hline \multicolumn{9}{|c|}{ NIST2709a and IAEA-155 SRMs } \\
\hline \multirow{3}{*}{$\mathrm{El}$} & \multicolumn{4}{|c|}{$U$ of $K$} & \multicolumn{2}{|l|}{ Assigned } & \multirow[b]{2}{*}{ Zeta } & \multirow[b]{2}{*}{$E_{n}$} \\
\hline & & $n$ & $X_{L a b} \pm U n c \mathrm{Lab}$ & LD & $X_{\text {cert }} \pm U n c$. & Bias & & \\
\hline & & & & & $(k=1)$ & $\%$ & score & $(k=2)$ \\
\hline $\mathrm{Cl}$ & IAEA-155 & 13 & $71,369 \pm 2862$ & 5848 & $69,200 \pm 5163$ & 3.13 & 0.37 & 0.2 \\
\hline \multirow{2}{*}{$\mathrm{K}$} & NIST2709a & 8 & $23,381 \pm 1163$ & \multirow{2}{*}{2571} & $21,100 \pm 300$ & 10.8 & 1.90 & 0.95 \\
\hline & IAEA-155 & 13 & $41,914 \pm 1229$ & & $41,700 \pm 16,327$ & 0.51 & 0.01 & 0.01 \\
\hline \multirow[b]{2}{*}{$\mathrm{Ca}$} & NIST2709a & 8 & $19,673 \pm 1452$ & \multirow[b]{2}{*}{937} & $19,100 \pm 450$ & 3.00 & 0.38 & 0.19 \\
\hline & IAEA-155 & 13 & $41,632 \pm 1229$ & & $42,100 \pm 5163$ & -1.11 & 0.09 & 0.04 \\
\hline $\mathrm{Ti}$ & NIST2709a & 8 & $3637 \pm 162$ & 314 & $3360 \pm 35$ & 8.3 & 1.68 & 0.84 \\
\hline $\mathrm{Mn}$ & NIST2709a & 8 & $486 \pm 36$ & 106 & $529 \pm 9.0$ & -8.1 & -1.17 & 0.58 \\
\hline \multirow[b]{2}{*}{$\mathrm{Fe}$} & NIST2709a & 8 & $34,005 \pm 892$ & \multirow[b]{2}{*}{42} & $33,600 \pm 350$ & 1.20 & 0.42 & 0.21 \\
\hline & IAEA-155 & 13 & $67 \pm 13$ & & $62 \pm 36$ & 7.8 & 0.13 & 0.07 \\
\hline $\mathrm{Ni}$ & NIST2709a & 8 & $78.4 \pm 6.7$ & * & $85 \pm 1.0$ & -7.8 & -0.98 & 0.49 \\
\hline \multirow[b]{2}{*}{$\mathrm{Zn}$} & NIST2709a & 8 & $111 \pm 6$ & \multirow[b]{2}{*}{7.9} & $103 \pm 2.0$ & 7.34 & 1.23 & 0.62 \\
\hline & IAEA-155 & 13 & $35 \pm 2$ & & $34.3 \pm 5.2$ & 1.91 & -6.03 & 0.06 \\
\hline \multirow{2}{*}{$\mathrm{Rb}$} & NIST2709a & 8 & $100 \pm 8$ & \multirow[b]{2}{*}{2.2} & $99 \pm 1.5$ & 1.17 & 0.14 & 0.07 \\
\hline & IAEA-155 & 13 & $38 \pm 1$ & & $39.2 \pm 6.1$ & -4.34 & -6.34 & 0.14 \\
\hline $\mathrm{Br}$ & IAEA-155 & 13 & $39 \pm 1$ & 2.1 & $39.1 \pm 8$ & -1.63 & -4.58 & 0.04 \\
\hline \multirow[b]{2}{*}{$\mathrm{Sr}$} & NIST2709a & 8 & $239 \pm 6.5$ & \multirow[b]{2}{*}{1.7} & $239 \pm 30$ & 0.04 & 0.003 & 0.002 \\
\hline & IAEA-155 & 13 & $11 \pm 0.6$ & & $10.5 \pm 5$ & 5.84 & 0.122 & 0.061 \\
\hline Th & NIST2709a & 8 & $8.9 \pm 0.7$ & 2.6 & $10.9 \pm 0.1$ & -19 & -2.83 & 1.41 \\
\hline $\mathrm{Zr}$ & NIST2709a & 8 & $140 \pm 10.2$ & 1.5 & $195 \pm 23$ & -28 & -2.19 & 1.10 \\
\hline
\end{tabular}

El is element " $n$ " is number of replicate, $U_{l a b}$. is Laboratory combined standard uncertainty with $k=1$, "*” is Not calculated, $\mathrm{LD}$ is the lower detection limit of $U$ of $K$ XRF laboratory, $E_{n}$ is $E_{n}$-number test, All results in $\mathrm{mg} / \mathrm{kg}$.

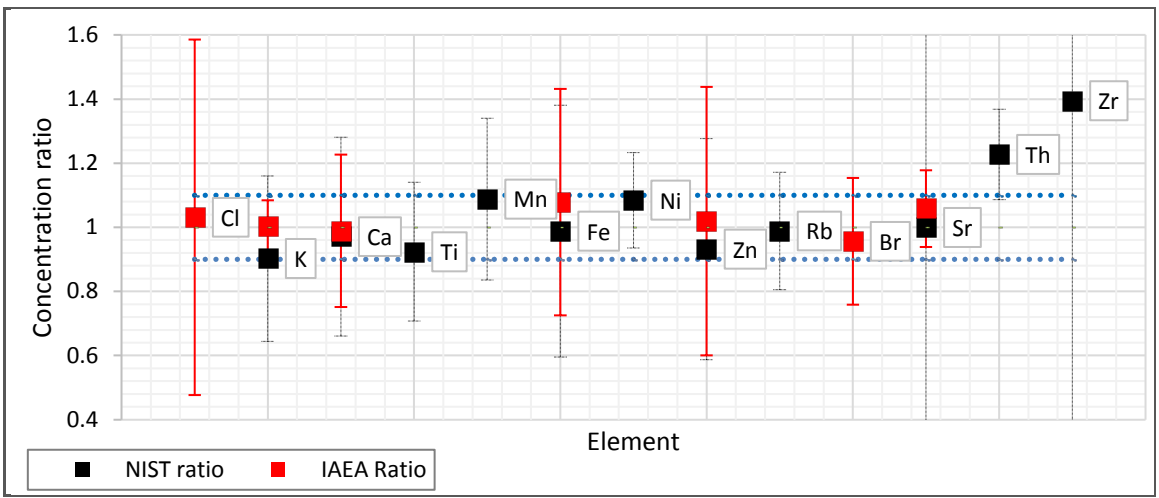

Figure 2. Ratio of certified values and obtained values for NIST2709a and IAEA-155 SRMs. 


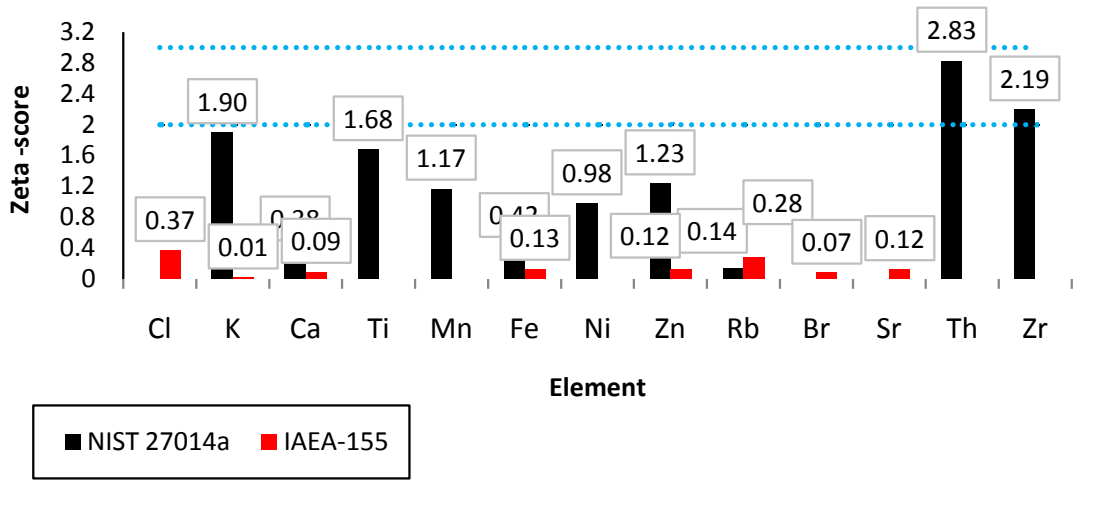

Figure 3. Zeta-score for NIST SRM-1573a and IAEA-155.

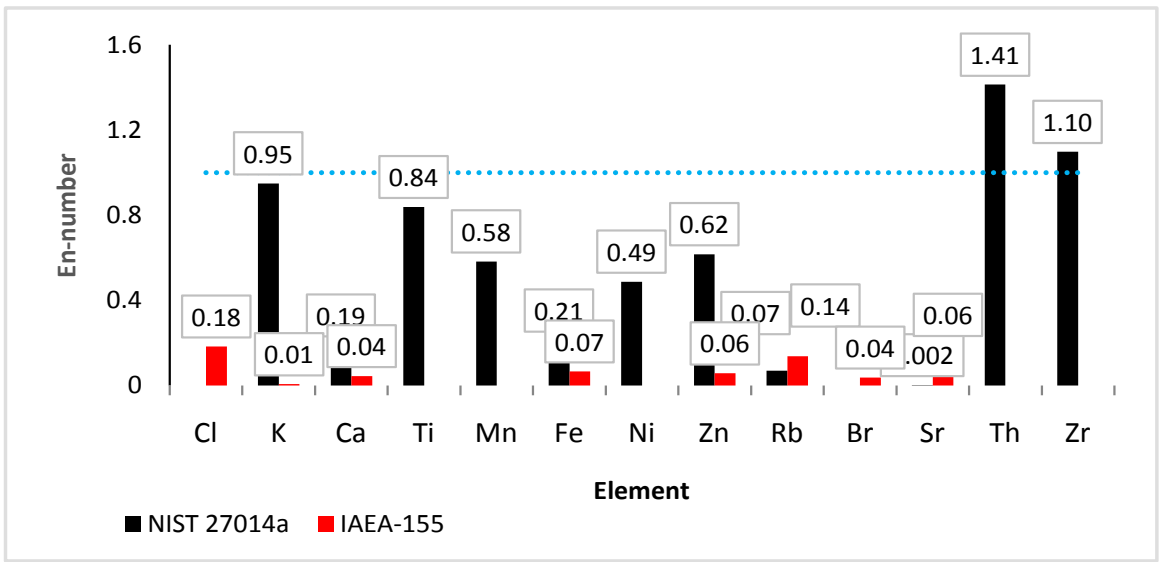

Figure 4. $E_{n}$ numbers obtained for NIST SRM-1573a and IAEA-155.

\section{Conclusion}

For the analysis, the suitable standard reference materials used were a set of 8 NIST-2709a (soil) and 13 IAEA-155 (milk powder) standards. The relative standard deviation (\%) of all interested elements were less than $15 \%$ except the $\mathrm{Ni}$ $(25.5 \%)$ and $\mathrm{Fe}(19.15 \%)$, because the concentrations of both elements are close to the detection limit. The total combined standards uncertainty values for XRF lab were estimated by a standard deviation of measurements adding $2.6 \%$ for error propagation related to the method. For accuracy assessment, three standard statistic approaches were applied, i.e. the Bias \%, zeta-score, and En-number. The bias of all elements for both SRMs generally within a deviation ranges from $-28 \%$ to $7.8 \%$. The results of all elements for both the zeta-score test and En-number have satisfactory results except Th (Thorium) and Zr (Zirconium) which consider as questionable results for NIST SRM 2709a and unsatisfactory results for En-number.

\section{Acknowledgements}

We wish to express deepest sincere gratitude to Sudan atomic energy commission for providing standard reference materials, and Dr. Radojko Jacimovic, from Jozef Stefan Institute, Slovenia for providing guidance. 


\section{References}

[1] Danesi Markowicz, P.R., Hase, N., Berger, L., Dargie, M., Tajani, A., Tchantchane, A. and Valkovic, V. (1996) Application of X-Ray Fluorescence Spectrometry in the Assessment of Environmental Pollution. Journal of Radioanalytical and Nuclear Chemistry, 206, 269-272. https://doi.org/10.1007/BF02039653

[2] Agency, I.A.E. (2005) In Sutu Applications of X-Ray Fluorescence Techniques. International Atomic Energy Agency, Vienna.

[3] Cesareo, R.B. (2012) X-Ray Fluorescence Spectrometry. ULLMANN'S Encyclopedia of Industrial Chemistry, 39, 595-629.

[4] Omote, J. (1995) CHIMICA X-Ray Fluorescence Analysis Utilizing the Fundamental Parameter Method for the Determination of the Elemental Composition in Plant Samples. Analytica Chimica Acta, 307, 117-126. https://doi.org/10.1016/0003-2670(95)00033-V

[5] Boyle, J.F. (2000) Rapid Elemental Analysis of Sediment Samples by Isotope Source XRF. Journal of Paleolimnology, 23, 213-221. https://doi.org/10.1023/A:1008053503694

[6] Stepen, A. and Wise, C. (2009) Certificate of Analysis, Standard Reference Material 2709a.

[7] Campbell, M.J. (2000) Trace Elements in Whey Powder. International Atomic Energy Agency, Vienna.

[8] ISO (2015) International Standard in Proficiency Testing by Interlaboratory Comparison Méthodes. International Organization for Standardization, Vernier.

[9] Taylor, B.N. and Kuyatt, C.E. (1994) Guidelines for Evaluating and Expressing the Uncertainty of NIST Measurement Results. Washington DC.

[10] Bell, S. (1999) A Beginner's Guide to Uncertainty of Measurement. Guides: Publications: National Physical Laboratory, 2, 41.

[11] JCGM (2008) Evaluation of Measurement Data-Guide to the Expression of Uncertainty in Measurement.

[12] Menezes, M.A. and Jaćimović, R. (2011) K0-INAA Quality Assessment by Analysis of Soil Reference Material GBW07401 Using the Comparator and Neutron Flux Monitor Approaches. Applied Radiation and Isotopes, 69, 1057-1063. https://doi.org/10.1016/j.apradiso.2011.03.002

[13] Bučar, T., Smodiš, B., Jaćimović, R. and Jeran, Z. (2008) Quality Assessment of K0-NAA by Statistical Evaluation of CRM Results. Acta Chimica Slovenica, 55, 166-171.

[14] Puerta, D.C., Figueiredo, A.M.G., Semmler, R. and Jaćimović, R. (2014) K0-INAA of Biological Matrices at IPEN Neutron Activation Analysis Laboratory, São Paulo, Using the K0-IAEA Software. Journal of Radioanalytical and Nuclear Chemistry, 300, 637-644. https://doi.org/10.1007/s10967-014-3035-Z 
Submit or recommend next manuscript to SCIRP and we will provide best service for you:

Accepting pre-submission inquiries through Email, Facebook, LinkedIn, Twitter, etc. A wide selection of journals (inclusive of 9 subjects, more than 200 journals)

Providing 24-hour high-quality service

User-friendly online submission system

Fair and swift peer-review system

Efficient typesetting and proofreading procedure

Display of the result of downloads and visits, as well as the number of cited articles Maximum dissemination of your research work

Submit your manuscript at: http://papersubmission.scirp.org/

Or contact wjnst@scirp.org 